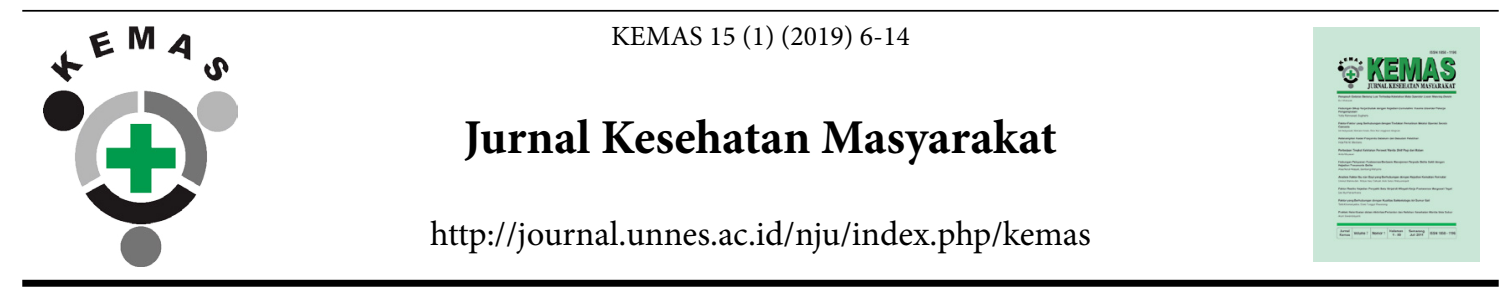

\title{
Occupational Respiratory Symptoms Caused by Chemical Hazard on Hairdresser Workers in Palembang
}

\author{
Desheila Andarini $^{1 凶}{ }^{\circledR}$ Anita Camelia ${ }^{1}$, Ani Nidia Listianti ${ }^{1}$ \\ ${ }^{1}$ Faculty of Public Health, Universitas Sriwijaya, Indonesia
}

\section{Article Info \\ Article History: \\ Submitted November 2017 \\ Accepted March 2019 \\ Published July 2019 \\ Keywords: \\ Occupational Respira- \\ tory Symptoms, Chemi- \\ cal Hazards, Hairdressers \\ DOI \\ https://doi.org/10.15294/ \\ kemas.v15i1.12111}

\begin{abstract}
Respiratory Disease is the leading cause of death in the majority of people and is among the top 10 causes of death in the world. Factors causing respiratory disease are occupational exposure, smoking and lung infections. According to WHO, 65 million people have respiratory illnesses ranging from moderate to severe. Nearly $90 \%$ of deaths from respiratory illness occur in low- and middle-income countries. Hairdressers are exposed to many chemicals in the use of many hair products such as shampoos, curling products, hair dyes, and hair sprays. This study aims to obtain risk factor related to occupational respiratory symptoms on hairdresser workers in Palembang. Cross sectional study design was chosen with a sample size of 150 respondents. The result showed that the prevalence of Occupational Respiratory Symptoms was $40 \%$, female hairdresser were $85.3 \%$, $64.7 \%$ were less than 35 years old, those with contact duration of eight hours a day was $78.7 \%$, and those with contact frequency of more than three times a day was $86.6 \%$. There were no significant relationship between sex, age and duration of contact with Occupational Respiratory Symptoms. There was a significant relationship between frequency of contact with Occupational Respiratory Symptoms..
\end{abstract}

\section{Introduction}

Respiratory Disease is the cause of death in majority of society and is included in the 10 major causes of death worldwide. Factors causing respiratory disease may increase Chronic Respiratory Disease (CRDS), among them are occupational exposure, smoking and pulmonary infection (WHO, 2002). Based on World Health Organization, respiratory disease is predicted to be the third highest killer by 2020 . Epidemiological studies have identified highrisk jobs and hazardous exposure, but there is still a lot of unknown exposure at work that can cause respiratory illnesses. In developed countries, respiratory disease is prevalent and some studies have shown a high risk of occupational diseases, such as occupational asthma, among workers due to exposure to gas and chemicals (Kogevinas et al., 1999).

Respiratory diseases caused by occupational exposure are called occupational lung disease. Occupational lung disease is a disease or disorder of the lung caused by inhalation of particles, fog, vapor or harmful gas when a person is working. The accumulation of such materials in the respiratory tract and the type of lung disease that occurs depend on the size and type of inhalation. Some types of particles that can cause lung disease are organic and inorganic particles, as well as gases and 
other aerosol materials such as gases from hydrocarbons, insecticidal chemicals, and gases from plastics and plastic burners. The time period for the onset of the disease is long; the shortest is five years. Inorganic particles, if inhaled in large quantities, can also cause lung disorders (Darmawan, 2013).

The hairdressing sector in Europe employs over one million people working in 400,000 salons and receives 350 million potential customers. Hairdressing services have more than $23 \%$ of the labor force, dominated by female workers i.e. $80 \%$ of the total worker are women. The majority of workers are dominated by young workers where more than $80 \%$ of workers are under 26 years old and 56\% are below 19 years (Hairdressers Registration Board of Western Australia, 2005). Workers in the hairdressing sector are at high risk for exposure to chemicals known to affect the respiratory system. Moreover, several studies have shown a positive risk of occupational asthma and other respiratory diseases (Schwartz HJ, 1990).

Hairdressers are exposed to many chemicals in the use of many products such as shampoo, curling products, hair dyes, and hair sprays. Several studies have been conducted on the health effects of this chemical exposure. The Agency for Research and Development of Cancer (IARC) conducts research and assessed that hair dyes is a carcinogenic substance and pose health hazard and cancer risk toward hair stylist (IARC, 1993). Previous studies showed poor workplace condition where over half of technical spaces to keep chemical substances used for dying and bleaching are manipulated and does not have any ventilation system or even a door or window opening to the outside (Mounier-Geyssant, Oury, Mouchot, Paris, \& Zmirou-Navier, 2006)

Occupational exposure to a variety of chemicals, which may be absorbed or inhaled, may affect the respiratory tract directly or cause bronchial mucosal inflammation in hair stylists. For example, persulfate salts cause occupational asthma and hyperresponsive airway through immunological mechanisms. Dyes and ammonia can cause mucous membrane irritation associated with occupational asthma and chronic bronchitis. "Hair-spray lung" (thesaurosis) has also been reported as a result of exposure to hair spray. Nasal airway obstruction may occur as a result of exposure to hair curling products. The increasing prevalence of asthma, respiratory symptoms, and total serum immunoglobulin is also reported in hair stylists exposed to bleaching powder, hair spray, hair curler and hair dye (Hashemi, 2010).

Respiratory problems and complaints in hair stylist workers based on preliminary research are chronic bronchitis, rhinitis, dyspnea, cough and phlegm, and the rising incidence of occupational asthma. A study conducted in Finland Salon indicated a relationship between work and incidence of respiratory symptoms. Moreover, personal protective equipment was found in most of the salons but very few of them provided masks or goggles (Nemer, Kristensen, Nijem, Bjertness, \& Skogstad, 2012)lung function, and knowledge of exposure to hazards among female Palestinian hairdressers.Cross-sectional study of female hairdressers and controls of female university students and staff. Working history and respiratory symptoms were collected using questionnaire. Lung function was measured. Working conditions were characterized in salons.A total of 170 hairdressers from 56 salons and 170 controls participated. Nineteen per cent of the hairdressers reported wheezing versus $11 \%$ in the control group. The mean forced vital capacity was 3.311 compared with 3.421 for controls. Adjusting for age and height, there was a forced expiratory volume in $1 \mathrm{~s}$ reduction of 0.0931 ( $95 \%$ confidence interval (CI.

Hairdressers who have worked for more than 40 years are found to have a high prevalence of some respiratory disorders compared to young hair stylist based on research conducted in Norway. Respiratory disorders in hairdressers in developed countries is commonly studied, but is rarely studied in developing countries like Indonesia. None has ever been conducted in the city of Palembang. Based on dangers due to exposure of chemicals used by hairdressers at work, it is important to conducted research on occupational respiratory symptoms caused by chemical hazard on hairdresser workers in Palembang.

\section{Method}

This study used survey method with 
cross sectional study design. This research was conducted with quantitative approach that aims to determine the prevalence and factors associated with Occupational Respiratory Symptoms in hairdressers in Palembang. The sample population was all residents that work as hairdressers in Palembang that is less and more than 35 years old. Sampling technique used was simple random sampling method from different subdistrict salons in Palembang.

This study was conducted in 18 subdistrict salons in Palembang. The study sample was hairdresser worker who had time for data collection and consented to participate in the research. The sample size of this study was 150 . Minimum sample size was calculated using previous proportion data from Novia, Stanbulli, and Victoria (2013) studies between the duration and frequency of exposure, length of service and illness. The results of the calculation was the number of samples should be 78 respondents for each group. We assumed there are two groups of respondents in the field; at risk group and not at risk group. Therefore, the minimum sample size that should be taken in the field should be 150 respondents.

In this study, primary data was collected by interview using questionnaire and observation. The data collection instruments used in this study was questionnaires containing questions to collect information according to the researcher's objectives, checklist of observation sheet, camera and stationery.

Variables analyzed were dependent and independent variables. The independent variable was occupational respiratory symptoms. The dependent variables were age, sex, contact duration, and contact frequency. Occupational respiratory symptoms was categorized into symptoms and no symptoms. Age was categorized into $\geq 35$ years and < 35 years. Sex was categorized into male and female. Contact duration was categorized into $\geq 8$ hours and $<8$ hours. Contact frequency was categorized into $\geq 3$ times and $<3$ times.

Data analysis was carried out using univariate and bivariate analysis. Univariate is used to describe independent variable and dependent variable. Data analysis is presented in the form of frequency distribution table and its interpretation. Bivariate analysis determined whether there is a relationship between two variables that are independent variables with dependent variable. The statistical test used is Chi-Square Test with degree of significance $(\alpha)$ of $5 \%$. This bivariate analysis will be performed using computer program for statistics.

\section{Results and Discussions}

Occupational respiratory disease is respiratory disease that is caused or exacerbated by work-related factors. In cases of nonmalignant and noninfectious occupational respiratory disease which is caused by work, the causative work factor becomes airborne in the work environment and is inhaled by the worker, usually over a prolonged period of time. Such airborne contaminants may exist in several forms, such as dust, mist, fibers, fume, vapor or gas. To be inhaled and cause diseases, such airborne contaminants in the workplace need to be what is known as 'respirable', i.e. small enough in size to gain access to the deeper, pulmonary areas of the lung. Work factors may also aggravate non-occupational respiratory conditions. Occupational respiratory symptoms could lead to occupational asthma. The major condition in this category is asthma, where it is known that factors such as exercise, stress, cold air, dust and other non-specific irritants can trigger attacks of asthma. Such trigger factors can be encountered in workplaces and, even though they are not the direct cause of the underlying respiratory disease, they can cause significant morbidity and, in severe cases, mortality (Australian Government, 2005).

Moscato et al., (2005) stated that hairdressers are at risk of occupational respiratory diseases. However, the risk factors, causal agents, and underlying mechanisms are not completely defined. Hairdressers are at risk of developing occupational respiratory disorders due to persulfate and other hairdressing chemicals (Lysdal, Mosbech, Johansen, \& Søsted, 2014). Based on Slater et al., (2000) hairdressers had a higher prevalence of asthma symptoms, diagnosed asthma, and asthma attacks in the previous 12 months.

Previous studies indicated that asthma and respiratory symptoms are common in hairdressers. This has been attributed to their exposure to a number of toxic elements used in the coiffures, including sprays, hair colors, and, 
more importantly, bleaching agents, specifically per sulfate salts, although the mechanism of inducing occupational asthma has not been definitely demonstrated. In addition, other risk factors such as smoking may confound the effect of these toxins on the development of respiratory symptoms (Skoufi, 2013). For many Indonesians, smoking is considered as an ordinary behavior, a part of social live and a lifestyle, without understanding the risk of smoking to their own and also other people's health. The smoker is unaware that they are trapped in tobacco addiction which cannot be easily cured. The rate of dissemination amongst first-timer smoker, specifically on young generation, was high; in some locations some toddlers have even begun smoking (Rosjidi, et al, 2017).

The number of hairdressers who have symptoms or respiratory complaints were 60 people $(40 \%)$. The symptoms consist of cough, shortness of breath, nasal congestion, and sore throat while working as hairdressers. According to Hollund, Moen, Lygre, Florvaag, \& Omenaas (2001), the hairdressers are exposed to low levels of various irritating chemicals every day and the prevalence of acute symptoms related to the exposure of hairdressers to hairdressing chemicals are very high. Occupational lung disease is a disease caused by continuous exposure to irritant or toxic substances, such as dust, vapors or gases that can induce acute or chronic respiratory diseases. Examples of occupational diseases are occupational asthma, mesothelioma and pneumoconiosis. Occupational asthma is an asthma caused or exacerbated by exposure in the workplace. Mesothelioma is a type of cancer caused by asbestos exposure. Pneumoconiosis is an occupational lung disease due to deposits of material in the lung causing damage to the alveoli .

Respiratory complaints or occupational respiratory symptoms are common and easily known: shortness of breath, cough, excess mucus production, hemoptysis, wheezing, and chest pain (Djojodibroto, 2009). Our study found that $40 \%$ of respondents have respiratory complaints at work such as symptoms of cough, shortness of breath, nasal congestion, sore throat, shortness of breath and cough accompanied by shortness of breath. This is in line with Slater's (2000) study which explains that hairdressers have a high prevalence of disease complaints and asthma attacks caused by decreased lung function. A cross-sectional survey of Greek hairdressers revealed that compared to office workers, hairdressers had more severe symptoms, such as dyspnea ( $\mathrm{P}$ $=0.03)$, irritation of the eye $(P=0.001)$ and throat $(P=0.007)$ which only occur at work which suggested work-related effects. However, the prevalence of different reported symptoms varied between different studies depending on the study methodology and tools. About $24 \%$ of the studied hairdressers in the current study reported wheezing. This was lower than previous studies in Norway (37 \%) and New Zealand ( $40 \%)$ while higher than in Turkey (15 $\%)$, France (8 and $10 \%)$ and Finland (4.8\%) (Hassan and Bayomy, 2015).

According to the Observatoire National des Asthmes Professionnels (ONAP) data, among people with occupational asthma, hairdressing represented the fourth most common occupation in both sexes, and the second most common occupation in women. The high rates of occupational asthma present

Table 1. The Relationship between Sex and Occupational Respiratory Symptoms

\begin{tabular}{|c|c|c|c|c|c|c|c|c|}
\hline \multirow{3}{*}{ Sex } & \multicolumn{3}{|c|}{$\begin{array}{l}\text { Occupational } \\
\text { Symptoms }\end{array}$} & piratory & \multirow{2}{*}{\multicolumn{2}{|c|}{ Total }} & \multirow{3}{*}{$P$ value } & \multirow{3}{*}{ PR 95\% CI } \\
\hline & \multicolumn{2}{|l|}{ Yes } & \multicolumn{2}{|l|}{ No } & & & & \\
\hline & $\mathrm{N}$ & $\%$ & $\mathrm{~N}$ & $\%$ & $\mathbf{N}$ & $\%$ & & \\
\hline Female & 50 & 33.3 & 78 & 52 & 128 & 85.3 & \multirow{3}{*}{0.572} & \multirow{3}{*}{$\begin{array}{l}0.769 \\
(0.309-1.913)\end{array}$} \\
\hline Male & 10 & 6.7 & 12 & 8.0 & 22 & 14.7 & & \\
\hline Total & 60 & 40 & 90 & 60 & 150 & 100 & & \\
\hline
\end{tabular}


not only in professional hairdressers, but also in their apprentices, who, compared to office apprentices, have been demonstrated to have poorer lung function, develop bronchial hyperresponsiveness and deterioration of lung function over a 3 year follow-up (Skoufi, 2013).

Statistical calculations on the relationship of sex with occupational respiratory symptoms obtained the following results:

The number of female respondents with occupational respiratory symptoms was $50(33.3 \%)$, whereas the number of male respondents with occupational respiratory symptoms were $10(6.7 \%)$. The remaining respondents who did not have occupational respiratory symptoms were 78 women $(52 \%)$ and 12 men (8\%). The p-value in table 2 above is 0.572 , which means that there is no significant relationship between sex and occupational respiratory symptoms. The majority of hair stylist workers were women (85.3\%). This is in line with research by Paskarini (2012) which stated that there is no relationship between sex variables with respiratory complaints in laborer of PT Lotus Indah Textile. Significantly less chronic cough, chronic phlegm as well as chronic bronchitis were found among women than among men after adjusting for smoking, age and duration of employment. Upper respiratory tract symptoms, by contrast, were more frequent in women than in men in these groups. Significant gender-related lung function differences also occurred in the textile industry but not in the food processing industry or among farmers (Schachter, 2009).

Statistical calculations on the relationship of age and occupational respiratory symptoms obtained the following results:
The number of respondentsaged $>35$ years and have occupational respiratory symptoms were 21 people (14\%), while respondents $<35$ years and have occupational respiratory symptoms were 39 (26\%). The remaining respondents who did not have occupational respiratory symptoms were 32 people $>=35$ $(21.3 \%)$ and 58 people $<35$ years $(38.7 \%)$. The p-value in table 7.2.2 above is 0.944 , meaning there is no significant relationship between age and occupational respiratory symptoms. Most hairdressers consist are younger than 35 years old $(64.7 \%)$.

Age is very influential on health. Age can increase risk if the age of workers are 2960 years, rendering them more susceptible to disruption or health complaints. Workers with pulmonary problems were found to be highest in the productive age group. This occurs because productive age person has high mobility and activity, so they are likely to be more exposed. In addition, this age group have risk factors for respiratory disorders such as smoking (Harnpicharnchai, 2006). This is in line with the research conducted by Hassan and Bayomy (2015) that hairdressers who reported respiratory, allergic or musculoskeletal symptoms were more likely to be older than those who did not. Based on Ferreia (2013), the majority of older hairdressers considered themselves to be in poorer health.

Statistical calculations on the relationship between duration of contact and respiratory symptoms at work obtained results as follows:

The number of respondents with duration of contact $\geq 8$ hours and had occupational respiratory symptoms were 43 people (28.7\%), whereas respondents with duration of contact $<8$ hours and had occupational respiratory

Table 2.The relationship between Age and Occupational Respiratory Symptoms

\begin{tabular}{|c|c|c|c|c|c|c|c|c|}
\hline \multirow{3}{*}{ Age } & \multicolumn{3}{|c|}{$\begin{array}{l}\text { Occupational } \\
\text { Symptoms }\end{array}$} & iratory & \multirow{2}{*}{\multicolumn{2}{|c|}{ Total }} & \multirow{3}{*}{$P$ value } & \multirow{3}{*}{ PR 95\% CI } \\
\hline & \multicolumn{2}{|c|}{ Yes } & \multicolumn{2}{|c|}{ No } & & & & \\
\hline & $\mathrm{N}$ & $\%$ & $\mathbf{N}$ & $\%$ & $\mathbf{n}$ & $\%$ & & \\
\hline$>=35$ year & 21 & 14 & 32 & 21.3 & 53 & 35.3 & & \\
\hline$<35$ year & 39 & 26 & 58 & 38.7 & 97 & 64.7 & 0.944 & 0.976 \\
\hline Total & 60 & 40 & 90 & 60 & 150 & 100 & & \\
\hline
\end{tabular}


Table 3.The Relationship Between Contact Duration and Occupational Respiratory Symptoms

\begin{tabular}{|c|c|c|c|c|c|c|c|c|}
\hline \multirow{3}{*}{$\begin{array}{l}\text { Contact } \\
\text { Duration }\end{array}$} & \multicolumn{4}{|c|}{$\begin{array}{l}\text { Occupational Respiratory } \\
\text { Symptoms }\end{array}$} & \multirow{2}{*}{\multicolumn{2}{|c|}{ Total }} & \multirow{3}{*}{$P$ value } & \multirow{3}{*}{ PR 95\% CI } \\
\hline & \multicolumn{2}{|l|}{ Yes } & \multicolumn{2}{|l|}{ No } & & & & \\
\hline & $\mathbf{N}$ & $\%$ & $\mathbf{N}$ & $\%$ & $\mathbf{n}$ & $\%$ & & \\
\hline$\geq 8$ hour & 43 & 28.7 & 75 & 50 & 118 & 78.7 & & \\
\hline$<8$ hour & 17 & 11.3 & 15 & 10 & 31 & 21.3 & 0.088 & $0.506(0.230-1.114)$ \\
\hline Total & 60 & 40 & 90 & 60 & 150 & 100 & & \\
\hline
\end{tabular}

symptoms were 17 people (11.3\%). The remaining respondents who did not have occupational respiratory symptoms were 75 people with contact $\geq 8$ hours (50\%) and 15 people with contact duration $<8$ hours $(10 \%)$. $\mathrm{P}$-value in table4 above is 0.088 , which means there is no significant relationship between age and occupational respiratory symptoms. The duration of contact of hairdresser workers with chemicals contained in equipment and materials used was more than eight hours a day (75.3\%). According to Ghasemkhani et al., (2006) age and duration of employment of workers and type of industry can be the cause of respiratory symptoms and are related to the prevalence of respiratory symptoms.

This is in line with Budiono's (2007) study which stated that the duration of contact of hazard-exposed activity can be used to estimate the cumulative exposure received by a worker. Occurrence of lung function impairment in workers greatly depend on the duration of exposure and the dose of exposure received. Hairdressers have a higher risk of cancer than the general population. The fact that this greater risk concerns different anatomical sites can be explained by the existence of multiple exposure pathways (respiratory, dermatological and systemic). Some cancers, such as lung and bladder cancer, may also share the same etiology, although most of them typically have an interval between the beginning of exposure and their onset (Deschamps, 2014).

Based on statistical calculations on the relationship of frequency of contact with occupational respiratory symptoms, the following results are obtained:

Number of respondents with contact frequency $\geq 3$ times and occupational respiratory symptoms were 59 people (39.3\%), while respondents with contact frequency $<3$ times and have occupational respiratory symptoms were $0.7 \%$. The remaining respondents who did not have occupational respiratory symptoms were 76 people with contact frequency $\geq 3$ times $(50.7 \%)$ and 14 people with contact frequency $<3$ times $(9.3 \%)$. The $\mathrm{p}$-value in table 7.2.4 above is 0.005 , meaning there is a significant relationship between contact frequency and occupational respiratory symptoms. The frequency of respondents' contact is more than three times a day (90\%). The more workers exposed to hazards, the higher the risk of respiratory distress (Eagan, 2002).

Consideration must be given to those hairdressers who, due to the impact of health

Table 4.The Relationship between Contact Frequency and Occupational Respiratory Symptoms

\begin{tabular}{|c|c|c|c|c|c|c|c|c|}
\hline \multirow{3}{*}{$\begin{array}{l}\mathrm{C} \text { o } \mathrm{n} \mathrm{t} \text { a } \mathrm{ct} \\
\text { Frequency }\end{array}$} & \multicolumn{3}{|c|}{$\begin{array}{l}\text { Occupational } \\
\text { Symptoms }\end{array}$} & Respiratory & \multirow{2}{*}{\multicolumn{2}{|c|}{ Total }} & \multirow{3}{*}{$P$ value } & \multirow{3}{*}{ PR 95\% CI } \\
\hline & \multicolumn{2}{|l|}{ Yes } & \multicolumn{2}{|c|}{ No } & & & & \\
\hline & $\mathbf{N}$ & $\%$ & $\mathbf{N}$ & $\%$ & $\mathbf{n}$ & $\%$ & & \\
\hline$\geq 3$ times & 59 & 39.3 & 76 & 50.7 & 135 & 90 & & \\
\hline$<3$ times & 1 & 0.7 & 14 & 9.3 & 15 & 10 & 0.005 & $\begin{array}{l}10.868 \\
1.380 .85023)\end{array}$ \\
\hline Total & 60 & 40 & 90 & 60 & 150 & 100 & & \\
\hline
\end{tabular}


concerns, are no longer working in this occupation. When workers remove themselves from an occupation due to poor health, the population that remain working tends to be healthier. This is a phenomenon known as the healthy worker effect in epidemiological studies (Nishikitani et al., 2012). Studies of workplace risks that have non-fatal health outcomes, such as asthma, are particularly likely to be effected by this bias as workers leave the occupation and transfer to a less-exposed environment (Farrow \& Reynolds, 2012). The frequency and severity of respiratory symptoms was also affected by the type of chemicals that the hairdressers had been exposed to. The most common products in the majority of the hair salons were hair dye, hair sprays, permanent wave solution, and bleaching powder. Exposure to these chemicals during work induced cough, breathlessness, and sneezing among hairdressers. The bleaching powder and hair spray were reported as the most irritating chemicals for respiratory symptoms (Hashemi, 2010).

Hairdressing is associated with increased risk to respiratory and musculoskeletal disorders due to adverse work conditions (Hassan \& Bayomy, 2015)hairdressing activities, the presence of respiratory symptoms and the prevalence of musculoskeletal pain in the past 12 months. Reported symptoms were compared between hairdressers and controls. The associations between selfreported symptoms and hairdressing activities were investigated. Hairdressers were more likely to report symptoms than controls particularly for those who were older, with higher body mass index and longer duration of work as hairdresser. There were significant associations between frequent hair treatments (bleaching, dye and wave. Specifically, the use of bespoke ventilation systems would seem to be a priority, as well as the introduction of practical technician training covering measures to protect the health of workers (HarrisRoberts et al., 2011). Hairdressers who perform hair bleaching treatments or using hair spray most frequently, have higher incidence of asthma (Albin et al., 2002)and a stratified sample of women from the general population were referents. A postal questionnaire included questions on respiratory tract symptoms, atopy, smoking, working periods as a hairdresser, and number of specific hair treatments performed/ week. Reported exposures were validated by occupational hygienists. Rate ratios of incidence (IRRs

Chemical and other hazards should be reduced through product and equipment redesign (Roelofs, C., Azaroff, L.S., Holcroft, C. et al, 2008). Bradshaw, Harris-Roberts, Bowen, Rahman, \& Fishwick (2011)compared to non-hairdressing controls.Methods An interviewer-led questionnaire recording demographic information, work history, health training levels and the presence of selfreported respiratory, skin, musculoskeletal and non-specific symptoms was administered. Results In total, 147 hairdressers, $86 \%$ of whom were female (median age 27 years reported that respiratory symptoms in hairdressers necessitates the development of training that informs hairdressers about the health risks of their work.

\section{Conclusions}

In this study, we found that the prevalence of occupational respiratory symptoms of hairdressers in Palembang was $40 \%$ and they are vulnerable groups. There was no relationship between contact duration, age and sex with occupational respiratory symptoms of hairdressers. However, there was a relationship between the frequency of contact with occupational respiratory symptoms of hairdressers. The possible hazard for hairdressers should be managed according to hazard control hierarchy and regulation for informal worker health should be conducted by the government.

\section{References}

Albin, M., Rylander, L., Mikoczy, Z., Lillienberg, L., Dahlman Höglund, A., Brisman, J., Nielsen, J. 2002. Incidence of asthma in female Swedish hairdressers. Occupational and Environmental Medicine, 59(2), 119 LP-123. https://doi.org/10.1136/oem.59.2.119

Australian Government. 2005. Occupational Respiratory Disease in Australia. Australian Safety and Compensation Council.

Bradshaw, L., Harris-Roberts, J., Bowen, J., Rahman, S., \& Fishwick, D. 2011. Self-reported work-related symptoms in hairdressers. Occupational Medicine, 61(5), 328-334. https://doi.org/10.1093/occmed/kqr089 
Djojodibroto. Respirology, Jakarta, EGC.

Eagan, Gulsvik, Eide and Bakke. 2002. Occupational Airborne Exposure and The Incidence of Respiratory Symptoms and Asthma. American Journal of Respiratory and Critical Care Medicine, Vol. 166, No.7

Deschamps, Langrand and Lesage. 2014. Health Assessment of Self-Employed Hairdressers in France. Journal of Occupational Health, Vol. 56, No.2

Farrow A, Reynolds F. 2012. Health and safety of the older worker. Occupational Medicine, 62(1):4-11.

Ferreira. 2013. An Assessment of Occupational Health Risks in Female Hairdressers Forefront to Xenobiotics. Rev. Bras. Farm. 94 (3): 190 $-198$.

Ghasemkhani, M., Kumashiro, M., Rezaei, M., Anvari, A. R., Mazloumi, A., \& Sadeghipour, H. R. 2006. Prevalence of Respiratory Symptoms among Workers in Industries of South Tehran, Iran. Industrial Health, 44(2), 218-224. https://doi.org/10.2486/ indhealth.44.218

Hairdressers Registration Board of Western Australia. 2005. Hairdressers Guide to Occupational Safety and Health.

Harnpicharnchai. 2006. A Study of Factors Affecting the Pulmonary Function Impairment of Rice Mill Workers.

Hashemi, et al. 2010. Occupational Exposures and Obstructive Lung Disease: A Case Control Study in Hairdressers. Journal of Respiratory Care, Vol. 55 No.7.

Harris-Roberts, J., Bowen, J., Sumner, J., StocksGreaves, M., Bradshaw, L., Fishwick, D., \& Barber, C. M. 2011. Work-related symptoms in nail salon technicians. Occupational Medicine, 61(5), 335-340. https://doi. org/10.1093/occmed/kqr096

Hassan, O. M., \& Bayomy, H. 2015. Occupational Respiratory and Musculoskeletal Symptoms among Egyptian Female Hairdressers. Journal of Community Health, 40(4), 670679. https://doi.org/10.1007/s10900-0149983-y

Hollund, B. E., Moen, B. E., Lygre, S. H., Florvaag, E., \& Omenaas, E. 2001. Prevalence of airway symptoms among hairdressers in Bergen, Norway. Occupational and Environmental Medicine, 58(12), 780 LP-785. https://doi. org/10.1136/oem.58.12.780

IARC. 1993. Occupational Exposures of Hairdressers and Barbers and Personal Use of Hair Colourants : Some Hair Dyes, Cosmetic Colourants, Industrial Dyestuffs and Aromatic Amines. IARC Monographs on The Evaluation of Carcinogenic Risks to Humans, 57.

Kurniawidjaja, M. 2010. Theory and Occupational Health, Jakarta, UI Press.

Kogevinas, M., Antó, J. M., Sunyer, J., Tobias, A., Kromhout, H., \& Burney, P. 1999. Occupational asthma in Europe and other industrialised areas: a populationbased study. The Lancet, 353(9166), 1750-1754. https://doi.org/10.1016/S01406736(98)07397-8

Lemeshow. 1997. Sample Size in Health Research. Yogyakarta, Gadjah Mada University Press.

Lysdal, S. H., Mosbech, H., Johansen, J. D., \& Søsted, H. 2014. Asthma and respiratory symptoms among hairdressers in Denmark: Results from a register based questionnaire study. American Journal of Industrial Medicine, 57(12), 1368-1376. https://doi.org/10.1002/ ajim. 22390

Moscato, G., Pignatti, P., Yacoub, M. R., Romano, C., Spezia, S., \& Perfetti, L. 2005. Occupational asthma and occupational rhinitis in hairdressers. Chest, 128. https://doi. org/10.1378/chest.128.5.3590

Mounier-Geyssant, E., Oury, V., Mouchot, L., Paris, C., \& Zmirou-Navier, D. 2006. Exposure of hairdressing apprentices to airborne hazardous substances. Environmental Health, $5(1), \quad 23 . \quad$ https://doi.org/10.1186/1476069X-5-23

Mooney, G. P. 2007. Respiratory Assesment [Online]. [Accessed 30 April 2017].

Nemer, M., Kristensen, P., Nijem, K., Bjertness, E., \& Skogstad, M. 2012. Respiratory function and chemical exposures among female hairdressers in Palestine. Occupational Medicine, 63(1), 73-76. https://doi. org/10.1093/occmed/kqs190

Nishikitani M, Nakao M, Tsurugano S, Yano E. 2012. The possible absence of a healthy-worker effect: a cross-sectional survey among educated Japanese women. British Medical Journal, 2(5):pii: e000958.

Roelofs, C., Azaroff, L.S., Holcroft, C. et al. J Immigrant Minority Health. 2008 10: 353. https://doi.org/10.1007/s10903-007-90844

Rosjidi, et al. 2017. Differences in Risk Factor of Cardiovascular Disease Risk on Rural and Urban Population . Kemas Unnes Journal 13(1), 69-76.

Schachter, et al. 2009. Gender and Respiratory Findings in Workers Occupationally Exposed to Organic Aerosols: A Meta Analysis 
of 12 Cross Sectional Studies. Journal of Environmental Health, Vol. 8

Schwartz Hj, A. B., Kingman P, Storhl Md. 1990. Occupational Allergic Rhinitis In The Hair Care Industry: Reactions To Permanent Wave Solutions. Journal Occupational Medicine.

Skoufi, et al. 2013. Work Related Respiratory Symptoms and Airway Disease in Hairdressers. Journal of Occupational Environmental Medicine, Vol. 4, 53-60.

Slater, T., Bradshaw, L., Fishwick, D., Cheng, S., Kimbell-Dunn, M., Erkinjuntti-Pekkanen, R., Pearce, N. 2000. Occupational respiratory symptoms in New Zealand hairdressers.
Occup Med, 50. https://doi.org/10.1093/ occmed/50.8.586

T Leino, L. T., R Luukkonen And H Nordman. 2006. Self Reported Respiratory Symptoms And Diseases Among Hairdressers. Occupational And Environmental Medicine, Volume 54, 452-455.

Ward, E. A. 2006. At A Glance Respiratory System, Jakarta, Erlangga.

World Health Organization. 2002. Strategy For Prevention And Control of Chronic Respiratory Diseases. Geneva: World Health Organization. 